\title{
Long-term $\mathrm{D}_{1}$-dopamine receptor sensitization in neonatal 6- OHDA-lesioned rats is blocked by an NMDA antagonist
}

\author{
Hugh E. Criswell, Robert A. Mueller, and George R. Breese \\ Biological Sciences Research Center, University of North Carolina School of Medicine, Chapel Hill, \\ NC 27599 (U.S.A.)
}

\begin{abstract}
Repeated administration of the $\mathrm{D}_{1}$-dopamine agonist SKF-38393 to adult rats having had dopaminergic neurons destroyed early in development results in an increasing enhancement of the behavioral response to SKF-38393 with each dose until a maximum is reached. This increased sensitivity lasts for at least 6 months. In the present study, this long-lasting change in behavioral responsiveness to repeated treatment with SKF-38393, referred to as $\mathrm{D}_{1}$-dopamine receptor priming, was shown to be dose dependent with smaller doses requiring an increased number of administrations to produce a maximal response when compared to higher doses. In addition, priming occurred equally well when treatment intervals ranged from 1 day to 14 days. These latter data reinforced the view that activation of $\mathrm{D}_{1}$-dopamine receptors results in a prolonged change in neural function. In subsequent experiments, $\mathrm{D}_{1}$-dopamine receptor priming was blocked by pretreatment with the NMDA-receptor antagonist MK-801. This antagonism of priming could not be attributed to a blockade of $\mathrm{D}_{1}$-dopamine receptors by MK- 801 or to the induction of interfering behaviors. Because an NMDA antagonist interfered with $\mathrm{D}_{1}$-receptor priming as it does with other long-term neural messages, a common requirement for these diverse forms of neuronal plasticity appears to involve activation of the NMDA receptor. This functional link between NMDA receptors and dopaminergic function and its relationship to neuronal plasticity could have relevance to the biochemical mechanisms involved in learning and to symptoms in central disorders during development that worsen over time, particularly those proposed to involve malfunctioning dopaminergic mechanisms.
\end{abstract}

\section{Keywords \\ $N$-Methyl-D-aspartate antagonist; Dopamine receptor; $\mathrm{D}_{1}$-receptor; $\mathrm{D}_{1}$-receptor priming; $\mathrm{D}_{1}$-receptor antagonist; Neonatal 6-OHDA-lesioned rat; Self-mutilatory behavior; Locomotor activity}

\section{INTRODUCTION}

Recently, our laboratory has reported an increasing functional sensitivity of $\mathrm{D}_{1}$-dopamine receptors upon repeated stimulation with the $\mathrm{D}_{1}$-dopamine receptor agonist SKF-38393 in rats lesioned as neonates with 6-hydroxydopamine (6-OHDA) ${ }^{6}, 14$. The behavioral activation that follows SKF-38393 administration to neonatal 6-OHDA-lesioned rats becomes greater with each dose and reaches a maximum intensity after 3-5 weekly treatments6. This change in sensitivity is still present 6 months after the last exposure to the $D_{1}$-dopamine agonist and is not dependent on cues associated with drug administration ${ }^{14}$ or to a change in dopamine receptor number or affinity ${ }^{7}$. This long-lasting change in the responsiveness to $\mathrm{D}_{1}$-dopamine 
receptor activation is referred to as priming ${ }^{6,14}$. There are two aspects of priming that have not been defined. These are the dose and the time parameters that will result in priming of the $\mathrm{D}_{1}$-dopamine receptor response. Therefore, one purpose of the present manuscript was to define these parameters for priming.

$\mathrm{D}_{1}$-dopamine receptor priming shares many properties with the enduring changes in synaptic sensitivity resulting from transient events which are thought to be the biological substrate for learning ${ }^{1-3,23}$. Recent work has demonstrated that spatial learning ${ }^{20}$, as well as models of longterm neural plasticity such as long-term potentiation ${ }^{15}$ observed upon stimulating pathways to the hippocampus ${ }^{12,13,16,18,20}$ and kindling produced by multiple stimulations of the amygdala ${ }^{4,10,19}$ can be blocked by $N$-methyl-p-aspartate (NMDA) receptor antagonists. These findings intimate that activation of the NMDA receptor, a glutamate receptor subtype, may be necessary for some types of neuronal plasticity. The similarity between the parameters controlling $\mathrm{D}_{1}$-dopamine receptor priming and those controlling other forms of neuronal plasticity suggested that these processes may share a common mechanism. Consequently, another set of investigations was undertaken to determine if blockade of NMDA receptors by MK-801 would alter priming of $\mathrm{D}_{1}$-dopamine receptors associated with repeated administration of SKF-38393.

\section{MATERIALS AND METHODS}

\section{General}

Pregnant Sprague-Dawley rats obtained from Charles River Laboratories Inc. (Raleigh, NC) were individually housed with Wayne Lab Blox laboratory chow and water available ad libitum until delivery of neonatal rats. At day 3 after delivery, each neonate was injected intracisternally under ether anesthesia with $100 \mu \mathrm{g}$ (free base) of 6-OHDA hydrobromide (Regis Chemical, Chicago, IL) dissolved in $10 \mu \mathrm{l}$ of saline8,22. Neonates were then returned to their mothers with litter size limited to 10 . Some neonates were pretreated with $20 \mathrm{mg} / \mathrm{kg}$ desmethylimipramine (Regis Chemical) $1 \mathrm{~h}$ prior to 6-OHDA injections to restrict the lesion to dopamine-containing neurons22. Rats were weaned at day 30 . Both male and female rats were used to evaluate the dose and time parameters in relationship to priming of $\mathrm{D}_{1}$-dopamine receptors. All other experiments used female rats. Because Criswell et al. ${ }^{14}$ did not find differences in priming between rats having only brain dopamine or both brain catecholamines reduced, rats from both of these treatment groups were used for the experiments in this investigation.

\section{Evaluation of locomotor activity and behavior}

Locomotor behavior was measured by placing rats in a circular photocell activity monitor ${ }^{17}$. Six photo sensors were placed about the periphery and counts from each sensor were collected by a microcomputer and recorded at $10 \mathrm{~min}$ intervals for $150 \mathrm{~min}$. Rats were habituated to the activity chamber for $1 \mathrm{~h}$ before administration of the dopamine agonist.

In one experiment, various behaviors were quantified by observing whether a behavior was seen during a 1-min period at 10 min intervals ${ }^{5}$. Each 1-min interval was divided into four 15$\mathrm{s}$ units to allow calculation of the percentage of the 15-s intervals a behavior was observed. This score was totalled for each behavior for the twelve 1-min observation periods.

\section{Drug treatment protocols}

Testing of rats was begun at 40-50 days of age. For the experiments dealing with time of administration, animals were given $3 \mathrm{mg} / \mathrm{kg}$ of SKF-38393, i.p., repeatedly at 1, 2, 7 or 14 day intervals for 4 doses. In order to evaluate dose relationships, rats were given a total dose of 9 $\mathrm{mg} / \mathrm{kg}$ of SKF-38393 divided such that one group received $9 \mathrm{mg} / \mathrm{kg}$ of SKF-38393 as a single 
dose, another group received three $3.0 \mathrm{mg} / \mathrm{kg}$ doses and a final group received six $1.5 \mathrm{mg} / \mathrm{kg}$ doses of SKF-38393. When more than one dose was necessary, the treatment interval was 4 days. Once these latter groups had been treated with an accumulated dose of $9 \mathrm{mg} / \mathrm{kg}, 3$ additional doses of $3 \mathrm{mg} / \mathrm{kg} \mathrm{SKF}-38393$ were administered at 4 day intervals and activity was measured after each drug dose.

In order to evaluate the effect of MK-801 on the priming of the SKF-38393 induced locomotor response, rats were given $0.1,0.3$ and $1 \mathrm{mg} / \mathrm{kg}$ of MK-801 $30 \mathrm{~min}$ prior to the injection of SKF-38393 (3 mg/kg). Another group of rats received saline rather than MK-801 with the SKF-38393. These drug combinations were given for a total of 4 treatments at weekly intervals. Once this regimen was completed, all rats were given 4 additional SKF-38393 $(3 \mathrm{mg} / \mathrm{kg})$ treatments to evaluate whether rats showing blockade of priming after the MK-801/SKF-38393 combination could now be primed. In addition, a group of rats was treated with MK-801 (0.3 $\mathrm{mg} / \mathrm{kg}$ ) plus SKF-38393 (3 mg/kg) and behavioral responses were recorded for $2 \mathrm{~h}$ after the administration of the $\mathrm{D}_{1}$-dopamine agonist as previously described5, ${ }^{14}$. This combination was given for 3 cycles at 3 day intervals, at which time SKF-38393 was administered alone and behavior was measured. Two additional doses of SKF-38393 were administered to establish which of the rats met our criteria for inclusion in the final statistical evaluation (see below). The behavioral responses for the MK-801/SKF-38393 treatment group were compared to the behavioral responses obtained after SKF-38393 administration to a group receiving their first dose and a group of neonatal-6-OHDA-lesioned rats already primed with SKF-38393. Another set of rats showing maximal behavioral responses to SKF-38393 were treated with $0.1,0.3$ or $1.0 \mathrm{mg} / \mathrm{kg}$ of MK-801 in order to see if the MK-801 blocked or influenced the SKF-38393 activity response. Additionally, the effect of $0.3 \mathrm{mg} / \mathrm{kg}$ MK- 801 on the response to quinpirole was measured in rats showing a supersensitive response to this $\mathrm{D}_{2}$-dopamine agonist.

\section{Drugs}

SKF-38393 (2,3,4,5-tetrahydro-7,8-dihydroxy-1-phenyl-1H-3-ben-zepine-7,8-diol (Smith Kline and French Laboratories, Philadelphia, PA); MK-801 ((+)-5-methyl-10,11dihydroxy-5H-dibenzo(a,d)cyclohepten-5,10-imine; Merck, Rahway, NJ); quinpirole (Lilly Research Laboratory, Indianapolis, IN); and Ro 4-4602 (Hoffmann-La Roche, Nutley, NJ); were dissolved in saline and administered intraperitoneally. L-DOPA (Hoffmann-La Roche, Nutley, NJ) was suspended in $0.5 \%$ carboxymethylcellulose and injected i.p.

\section{Statistical evaluation}

Locomotor activity was analyzed by summing the activity counts for 150 min and performing a repeated measures ANOVA on the totals. Individual comparisons of the experimental groups to controls were made with the Dunnett test ${ }^{24}$. Since previous data has documented that only rats which reach an asymptotic response to SKF-38393 totaling at least 10,000 counts/150 min have dopamine depletions of at least $90 \% 5,7$, only those rats meeting this behavioral criteria were used for analysis. The ratio of rats omitted to those retained was determined and the ratio for the groups that received only SKF-38393 was compared to that for the groups that were dosed with MK-801 + SKF-38393 using the test for the difference between proportions 9 . Behavioral series for groups were compared using analysis of variance. For each analysis that yielded a significant $F$ ratio, a Tukey HSD was applied to allow mean comparison of each behavior ${ }^{24}$. 


\section{RESULTS}

\section{Effect of repeated administration of SKF-38393 to neonatal 6-OHDA-lesioned rats at varying time intervals on activity}

Increasing locomotor activity as a function of repeated administration of the $\mathrm{D}_{1}$-dopamine agonist SKF-38393 at varying time intervals to adult rats lesioned with 6-OHDA as neonates is shown in Fig. 1. There was no difference in the rate of $D_{1}$-dopamine receptor priming when the 1,2, 7 and 14 day injection intervals were compared. These results indicated that the neural signal from a single injection can be observed when animals are challenged at 1 day intervals and that the consequence of the single treatment will last for at least 14 days.

\section{Effect of dose on the increased activity with repeated administration of SKF-38393 to neonatal 6-OHDA-lesioned rats}

Since a significant effect on activity can be observed after 3 doses of $3 \mathrm{mg} / \mathrm{kg}$ of SKF-38393, doses of $1.5,3$ or $9 \mathrm{mg} / \mathrm{kg}$ of SKF-38393 to accumulate a total dose of $9 \mathrm{mg} / \mathrm{kg}$ were administered at 4 day intervals except for $9 \mathrm{mg} / \mathrm{kg}$ where only a single dose was injected prior to additional challenges. The effects of increasing doses of SKF-38393 on the $\mathrm{D}_{1}$-dopamine receptor response with each dose are shown in Table I. The response to the first dose of SKF-38393 was dose dependent, but even the $9 \mathrm{mg} / \mathrm{kg}$ dose did not produce a response as great as that seen after multiple doses of 1.5 or $3.0 \mathrm{mg} / \mathrm{kg}$ (Fig. 2). It can also be seen that one dose of $9 \mathrm{mg} / \mathrm{kg}$ produced a greater increment in activity following a second dose of $3 \mathrm{mg} / \mathrm{kg}$ of SKF-38393 than did a single $3 \mathrm{mg} / \mathrm{kg}$ dose (Fig. 2; Table I). However, following 3 doses of 3 $\mathrm{mg} / \mathrm{kg}$ or 6 doses of $1.5 \mathrm{mg} / \mathrm{kg}$ of SKF-38393 (i.e. for a total cumulative dose of $9 \mathrm{mg} / \mathrm{kg}$ ) the difference between groups disappeared when given an additional challenge dose of $3 \mathrm{mg} / \mathrm{kg}$ (see after $9 \mathrm{mg} / \mathrm{kg}$, Fig. 2). No further significant increase occurred following 3 additional doses of $3 \mathrm{mg} / \mathrm{kg}$ (see asymptote, Fig. 2).

\section{Effect of MK-801 on $D_{1}$-dopamine receptor priming in neonatal 6-OHDA-lesioned rats}

Documentation of the long-term consequences of repeated doses of SKF-38393 led us to speculate that this priming phenomenon may share characteristics with other long-term adaptive changes. Fig. 3 shows that $0.3 \mathrm{mg} / \mathrm{kg}$ of MK-801 administered $30 \mathrm{~min}$ before each of 4 doses of SKF-38393 (3 mg/kg, i.p.) blocked the increasing behavioral activation usually produced by this compound (see Fig. 1 for increasing activity with each dose of SKF-38393 in the absence of MK-801). The fifth dose of SKF-38393 (S5; Fig. 3) administered without MK-801 likewise produced no major increase in activity, indicating that $\mathrm{D}_{1}$-dopamine receptor priming of this behavioral response was blocked. As shown in Fig. 4B, higher and lower doses of MK-801 (1.0 and $0.1 \mathrm{mg} / \mathrm{kg})$ also prevented the expected response to a fifth dose of SKF-38393. The activity response to SKF-38393 immediately following the MK-801/ SKF-38393 treatment (i.e. fifth dose) did not differ dramatically from that seen when a first dose of SKF-38393 was administered to naive rats (Fig. 4A). These observations indicated that $\mathrm{D}_{1}$-dopamine receptor priming did not occur in the presence of MK- 801 .

$D_{1}$-dopamine receptor priming following repeated administration of the MK-801/SKF-38393 combination to neonatal 6-OHDA-lesioned rats

Following the observation that MK-801 would antagonize the consequence of repeated administration of SKF-38393 to neonatal 6-OHDA-lesioned rats, it was then asked whether the animals that received the MK-801/SKF-38393 treatment would show $\mathrm{D}_{1}$-dopamine receptor priming if they then received an additional series of weekly injections of SKF-38393 alone. Responses to these additional doses of SKF-38393 in the absence of $0.3 \mathrm{mg} / \mathrm{kg}$ MK-801 are presented in Fig. 3 (e.g. S5-S9). It is apparent that by the third additional dose of SKF-38393 ( $3 \mathrm{mg} / \mathrm{kg}$ ) in the absence of MK-801 (i.e. S7; Fig. 3) SKF-38393 produced a significant increase 
in activity compared to the first dose after MK-801 treatment (i.e. S5; Fig. 3). This procedure of administering SKF-38393 without MK-801 was performed for the two other groups of rats previously dosed with the MK-801 ( 0.1 and $1.0 \mathrm{mg} / \mathrm{kg}) / \mathrm{SKF}-38393$ combination. Both groups demonstrated a significant increase in activity after 3-5 additional doses of SKF-38393, indicating that $\mathrm{D}_{1}$-dopamine receptor responses could be primed in these rats (see legend Fig. $3)$.

Since some rats could not be retained for analysis because they did not reach our behavioral criteria for supersensitivity after repeated administration of SKF-38393, the ratio of rats omitted to those retained was evaluated for the saline- and MK-801-pretreated rats. Six of 8 saline-treated rats subsequently primed with repeated SKF-38393 treatment, while the ratio for rats showing priming to those that did not when pretreated with $0.1,0.3$ and $1 \mathrm{mg} / \mathrm{kg}$ of MK-801 were 5 of 7, 7 of 8, and 4 of 5, respectively. None of the MK-801/SKF-38393 treated groups differed significantly from saline/SKF-38393 treated control group $(P>0.1)$.

An additional experiment was performed to determine if behaviors other than locomotion were being primed during repeated administration of the SKF-38393/MK-801 combination. As shown in Table II, the behavioral responses to SKF-38393 after the 3 MK-801/SKF-38393 treatments were similar to those observed after the first dose of SKF-38393 administered in the absence of MK-801 and were less than seen when SKF-38393 was administered alone to primed rats. This finding indicated that the priming of all behaviors induced by SKF-38393 repeat injection was being blocked when coadministered with MK-801.

\section{Effect of MK-801 on activity induced by SKF-38393 in primed rats}

Because the $\mathrm{D}_{1}$-dopamine receptor antagonist $\mathrm{SCH}-23390$ blocks both priming and the behavioral effects produced by SKF-38393 ${ }^{14}$, studies were undertaken to see if the blockade of priming by MK-801 might be due to an antagonism of SKF-38393-induced behavioral responses. This possibility was examined by using primed rats that had reached maximal supersensitivity to SKF-38393. As shown in Table III, 0.3 and $1.0 \mathrm{mg} / \mathrm{kg}$ of MK-801 produced ataxia and retarded SKF-38393-induced activity, whereas $0.1 \mathrm{mg} / \mathrm{kg}$ of MK-801 did not antagonize and actually increased the activity response following SKF-38393 administration. The reduced locomotor response to SKF-38393 after $0.3 \mathrm{mg} / \mathrm{kg}$ could not be interpreted as a specific action on $\mathrm{D}_{1}$-dopamine receptor because the increased locomotion induced by the $\mathrm{D}_{2}$-dopamine agonist quinpirole was also reduced by this dose of MK-801 (Table III). In addition, it should be noted that the activity response to the first dose of SKF-38393 in the presence of $0.1 \mathrm{mg} / \mathrm{kg}$ of MK-801 was significantly increased (Fig. 4A). This latter effect is due to a stimulant action of this dose of MK-801 (Criswell and Breese, unpublished data). In spite of the elevated activity when SKF-38393 and $0.1 \mathrm{mg} / \mathrm{kg}$ of MK-801 were coadministered, the response to SKF-38393 alone following the repeated administration of the combination was significantly lower than that for the group treated with saline rather than MK-801 (Fig. 4B).

\section{DISCUSSION}

Previous work from this laboratory has demonstrated that repeated administration of the $\mathrm{D}_{1}$ dopamine agonist SKF-38393 at weekly intervals results in an increasing response with each dose - a phenomenon referred to as priming ${ }^{6,14}$. In the present investigation, additional information about this phenomenon was sought. It was demonstrated that priming could be exhibited if doses of the agonist were administered at one to 14 day intervals. The fact that priming could be observed when doses of SKF-38393 were administered at 14 day intervals clearly documents the long term contribution of each dose to the priming process. Further, the effectiveness of the accumulated action of SKF-38393 indicates that decay of the signal must be minimal. Previous data have demonstrated that once the maximal response is reached, the 
primed response persists for at least 6 months ${ }^{14}$. The present investigation also documented that priming of the $\mathrm{D}_{1}$-dopamine receptor response occurred when the SKF-38393 was administered at one-day intervals. This observation provides additional evidence that this enhanced sensitivity with repeated dosing of SKF-38393 differs from such a change in sensitivity observed after repeated administration of ${ }_{\mathrm{D}}$-amphetamine. In contrast to SKF-38393, weekly inter-injection intervals of $\mathrm{D}$-amphetamine produce greater behavioral sensitization than does daily administration ${ }^{21}$.

The $\mathrm{D}_{1}$-dopamine antagonist $\mathrm{SCH}-23390$ blocks priming of the $\mathrm{D}_{1}$-dopamine receptor response, whereas the $\mathrm{D}_{2}$-dopamine receptor antagonist haloperidol blocks neither the behavioral effects of SKF-38393 nor the subsequent priming of $\mathrm{D}_{1}$-dopamine receptor supersensitivity ${ }^{14}$. This observation points out that not all dopamine antagonists block priming and emphasizes the importance of $\mathrm{D}_{1}$-dopamine receptor activation to this phenomenon. In the present study, MK-801 was found to antagonize priming. However, there are several observations suggesting that the action of MK-801 is not due to a direct action on dopamine receptors. For example, MK-801 does not displace $\left[{ }^{3} \mathrm{H}\right]$ spiperone or $\left[{ }^{3} \mathrm{H}\right]$ apomorphine from striatal tissue ${ }^{11}$. The lowest dose of MK-801 employed in the present study blocked $\mathrm{D}_{1^{-}}$ dopamine receptor priming without diminishing the behavioral activating effect of SKF-38393, indicating that a blockade of the behavioral activating effect of SKF-38393 is not necessary for the prevention of priming. The fact that a higher dose of MK-801 antagonized the response of both SKF-38393 and quinpirole and caused ataxia suggests that the inhibition of SKF-38393induced locomotion is the result of the motor incoordination produced by this dose of MK-801 and not a specific action on $\mathrm{D}_{1}$-dopamine receptor function. Another potential explanation for the data demonstrating an MK-801 antagonism of priming of SKF-38393-induced locomotion was that the treatment with MK-801 enhanced SKF-38393-induced priming of other behaviors that would be incompatible with the occurrence of activity (i.e. behavioral competition). An experiment to test this view indicated that specific behaviors induced by SKF-38393 were not being enhanced or preferentially primed when SKF-38393 was given in combination with MK-801. Thus, neither a blockade of $\mathrm{D}_{1}$-dopamine receptor function nor the production (i.e. priming) of interfering behaviors with repeated MK-801/SKF-38393 treatment can explain the reduced activity found for the first dose of SKF-38393 given after the MK-801/SKF-38393 combination.

As described in the introductory remarks, several examples of long-term change in neuronal sensitivity have been postulated to depend upon activation of the NMDA receptor. The ability of the NMDA-receptor antagonist MK-801 25,26 to block development of supersensitivity to repeated $\mathrm{D}_{1}$-dopamine receptor agonist administration suggests that activation of the NMDA receptor is necessary for the occurrence of $\mathrm{D}_{1}$-dopamine receptor priming. Since previous work ${ }^{14}$ has shown that the $\mathrm{D}_{1}$-dopamine antagonist $\mathrm{SCH}-23390$ blocks priming, the concomitant activation of both $\mathrm{D}_{1}$-dopamine receptors and NMDA receptors appear necessary for priming to occur. The indication that NMDA receptor activation is also a necessary prerequisite for other responses that convey a long-term neural message, such as learning ${ }^{20}$ and long-term potentiation $12,13,16,18$, suggests that these phenomena and $\mathrm{D}_{1}$-dopamine receptor priming may share a common biochemical mechanism.

Because the increasing behavioral sensitivity to SKF-38393 induced locomotor activation (i.e. priming) in neonatal 6-OHDA-lesioned rats is associated with the activation of a specific neural receptor6,14 as well as a defined anatomical locus14, priming can be easily controlled and investigated. These characteristics and the finding that priming shares a relationship with other types of long-lasting neural plasticity through an involvement of NMDA receptors may facilitate efforts to delineate the nature of the cellular biochemical change(s) that underlie such long-term neural events. Obviously, the most important of these processes is learning. It should be understood that this conclusion is based upon the assumption that the biochemical 
mechanism by which neurons induce a long lasting neural plasticity is common for differing types of neurons. Regardless, the data presented here concerning the enhanced behavioral sensitivity observed with repeated stimulation of $\mathrm{D}_{1}$-dopamine receptors provide further functional evidence for the view that NMDA receptors may be involved in critical biochemical processes responsible for long-term plasticity changes in the CNS.

\section{Acknowledgments}

The authors acknowledge the excellent assistance of Ms. Doris Lee in the typing of this manuscript. Work in this manuscript is supported by USPHS Grants NS-21345, HD-23042 and HD-03110.

\section{REFERENCES}

1. Barnes CA. Spatial learning and memory processes: the search for their neurobiological mechanisms in the rat. Trends Neurosci 1988;11:163-169. [PubMed: 2469185]

2. Bliss TVP, Lomo T. Long-lasting potentiation of synaptic transmission in the dentate area of the anesthetized rabbit following stimulation of the perforant path. J. Physiol. (Lond.) 1972;232:331-356. [PubMed: 4727084]

3. Bliss TVP, Gardner-Medwin AR. Long-lasting potentiation of synaptic transmission in the dentate area of the unanesthetized rabbit following stimulation of the perforant path. J. Physiol. (Lond.) 1973;332:357-374. [PubMed: 4727085]

4. Bowyer JF. Phencyclidine inhibition of the rate of kindling development. Exp. Neurol 1982;75:173183. [PubMed: 7199477]

5. Breese GR, Baumeister AA, McCown TJ, Emerick SG, Frye GD, Crotty K, Mueller RA. Behavioral differences between neonatal and adult-6-hydroxydopamine-treated rats to dopamine agonists: relevance to neurological symptoms in clinical syndromes with reduced brain dopamine. J. Pharmacol. Exp. Ther 1984;231:343-354. [PubMed: 6149306]

6. Breese GR, Napier TC, Mueller RA. Dopamine agonist-induced locomotor activity in rats treated with 6-hydroxydopamine at differing ages: functional supersensitivity of D-1 dopamine receptors in neonatally lesioned rats. J. Pharmacol. Exp. Ther 1985;234:447-455. [PubMed: 3926987]

7. Breese GR, Duncan GE, Napier TC, Bondy SC, Iorio LC, Mueller RA. 6-Hydroxydopamine treatments enhance behavioral responses to intracerebral microinjection of $\mathrm{D}_{1}$ - and $\mathrm{D}_{2}$-dopamine agonists into nucleus accumbens and striatum without changing dopamine antagonist binding. J. Pharmacol. Exp. Ther 1987;240:167-176. [PubMed: 3100767]

8. Breese GR, Traylor TD. Developmental characteristics of brain catecholamines and tyrosine hydroxylase in the rat: effects of 6-hydroxydopamine. Br. J. Pharmacol 1972;44:210-222. [PubMed: 4148915]

9. Bruning JL, Kintz BL. Test for significance of difference between two proportions. Computational Handbook of Statistics 1968:199-204.

10. Callaghan DA, Schwark WS. Pharmacological modification of amygdaloid-kindled seizures. Neuropharmacology 1980;19:1131-1136. [PubMed: 7442943]

11. Clineschmidt BV, William M, Witoslawski JJ, Bunting PR, Risley EA, Totara JA. Restoration of shock-suppressed behavior by treatment with (+)-5-methyl-10,11-dihydro-5H-dibenzo[a,d] cyclohepten-5,10-imine (MK-801), a substance with potent anticonvulsant, central sympathomimetic, and apparent anxiolytic properties. Drug Dev. Res 1982;2:147-163.

12. Collingridge GL, Kehl SJ, McLennan H. Excitatory amino acids in synaptic transmission in the Schäffer collateral-commissural pathway of the rat hippocampus. J. Physiol. (Lond.) 1983;334:3346. [PubMed: 6306230]

13. Collingridge GL, Bliss TVP. NMDA receptors - their role in long-term potentiation. Trends Neurosci 1987;10:288-293.

14. Criswell HE, Breese GR, Mueller RA. Priming of $\mathrm{D}_{1}$-dopamine receptor responses: long-lasting behavioral supersensitivity to $\mathrm{D}_{1}$-dopamine agonist following repeated administration to neonatal 6OHDA-lesioned rats. J. Neurosci 1989;9:125-133. [PubMed: 2521511] 
15. Goddard GV, McIntyre DC, Leech CK. A permanent change in brain function resulting from daily electrical stimulation. Exp. Neurol 1969;25:295-330. [PubMed: 4981856]

16. Harris EW, Ganong AH, Cottman CW. Long-term potentiation in the hippocampus involves activation of $N$-methyl-d-aspartate receptors. Brain Research 1984;323:132-137. [PubMed: 6151863]

17. Hollister AS, Breese GR, Cooper BR. Comparison of tyrosine hydroxylase and dopamine- $\beta$ hydroxylase inhibition with the effects of various 6-hydroxydopamine treatments on d-amphetamine induced motor activity. Psychopharmacologia 1974;36:1-16. [PubMed: 4151923]

18. Larson J, Lynch G. Role of $N$-methyl-d-aspartate receptors in the induction of synaptic potentiation by burst stimulation patterned after the hippocampal theta rhythm. Brain Research 1988;441:111118. [PubMed: 2896049]

19. McNamara JO, Russel RD, Rigsbee L, Bonhavs DW. Anticonvulsant and antiepileptogenic actions of MK-801 in the kindling and electroshock models. Neuropharmacology 1988;27:563-568. [PubMed: 2843782]

20. Morris RGM, Anderson E, Lynch G, Baudry M. Selective impairment of learning and blockade of long-term potentiation by an $N$-methyl-d-aspartate receptor antagonist, AP-5. Nature (Lond.) 1986;319:774-776. [PubMed: 2869411]

21. Robinson TE, Becker JB. Enduring changes in brain and behavior produced by chronic amphetamine administration: a review and evaluation of animal models of amphetamine psychosis. Brain Res. Rev 1986;11:157-198.

22. Smith RD, Cooper BR, Breese GR. Growth and behavioral changes in developing rats treated intracisternally with 6-hydroxydopamine: evidence for involvement of brain dopamine. J. Pharmacol. Exp. Ther 1973;185:609-613. [PubMed: 4145870]

23. Thompson RF. The neurobiology of learning and memory. Science 1986;233:941-947. [PubMed: 3738519]

24. Winer, RJ. Statistical Principles in Experimental Design. New York: McGraw-Hill; 1971.

25. Wong EHF, Knight AR, Woodruff GN. [ $\left.{ }^{3} \mathrm{H}\right] \mathrm{MK}-801$ labels a site on the $N$-methyl-d-aspartate receptor channel complex in rat brain membranes. J. Neurochem 1988;50:274-281. [PubMed: 2826686]

26. Wong EHF, Kemp JA, Priestley T, Knight AR, Woodruff GN, Iversen LL. The anticonvulsant MK-801 is a potent $N$-methyl-d-aspartate antagonist. Proc. Natl. Acad. Sci. U.S.A 1986;83:71047108. [PubMed: 3529096] 


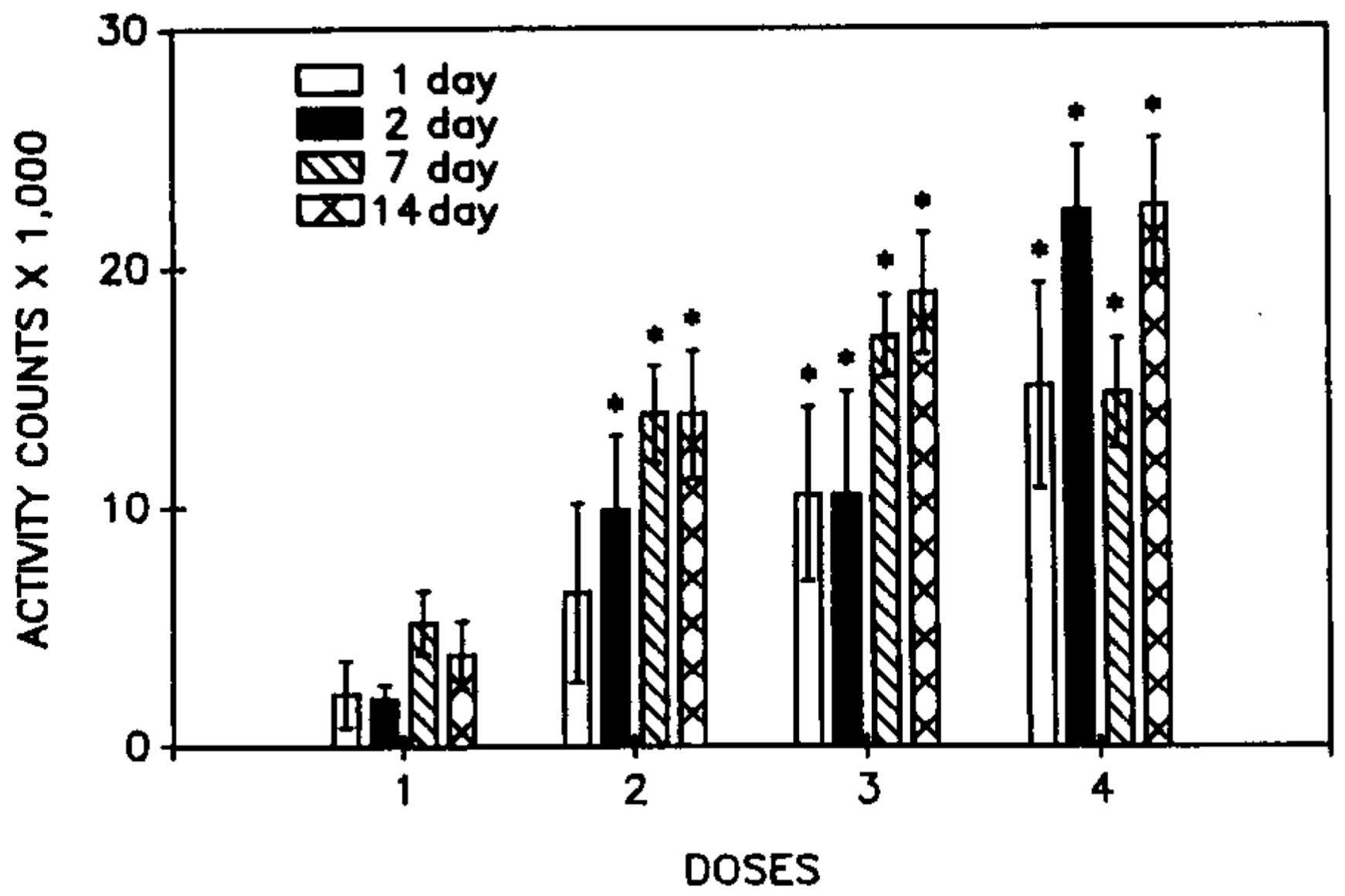

Fig. 1.

Activity following repeated administration of SKF-38393 at varying time intervals to neonatal 6-OHDA-lesioned rats with destruction of both dopaminergic and noradrenergic neurons. Rats received 4 consecutive $3 \mathrm{mg} / \mathrm{kg}$ i.p. injections of SKF-38393 at injection intervals of 1, 2, 7 or 14 days. Rats were habituated to the testing chamber for $50 \mathrm{~min}$ immediately prior to testing and total counts are shown for a 150 min period. $\mathrm{D}_{1}$-dopamine receptor priming occurred at similar rates and reached a similar final sensitivity for all groups $(P>0.1$ for time interval by dose number interaction). ${ }^{*} P<0.05$ when compared to dose 1 for that group. 


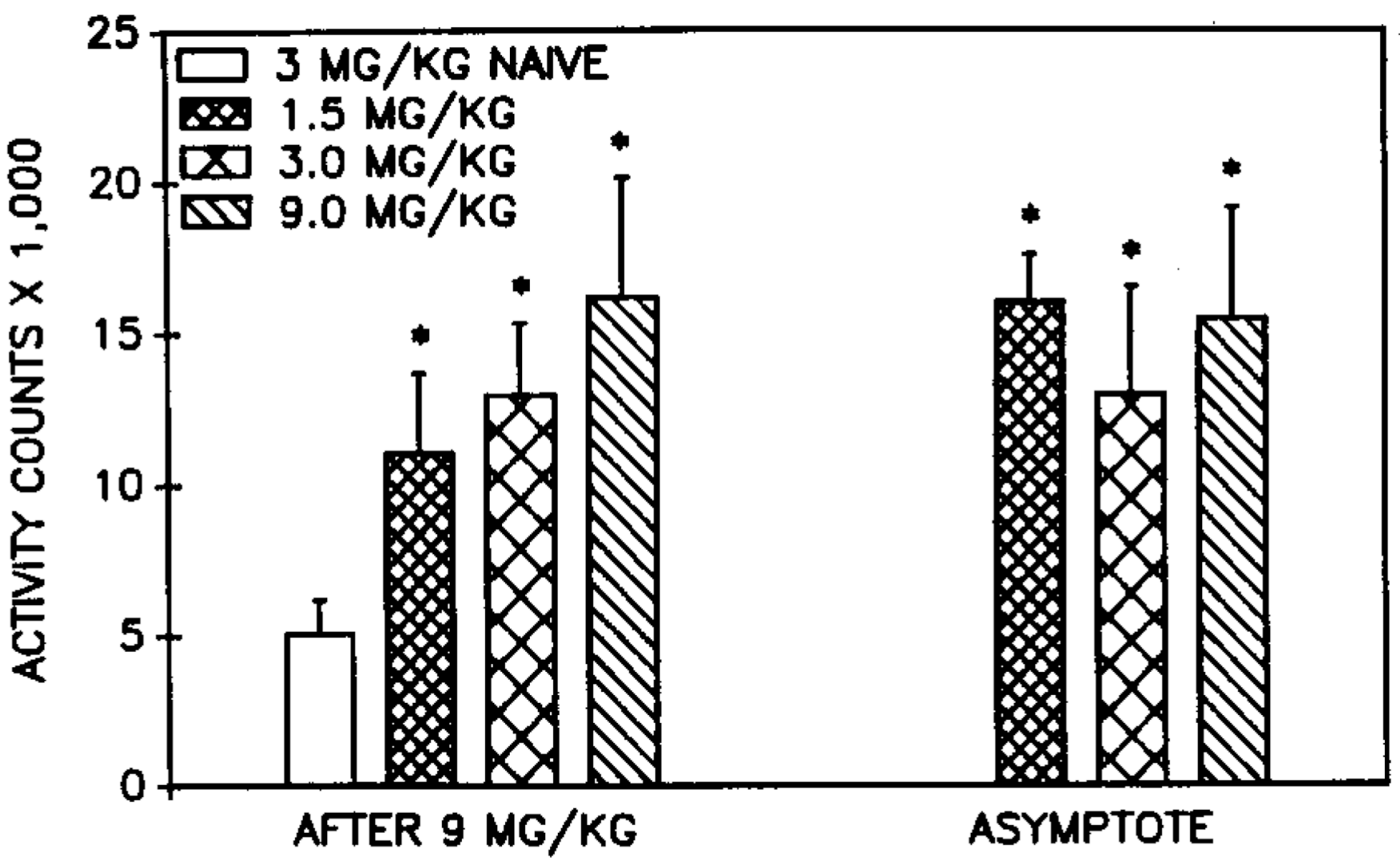

Fig. 2.

Effect of varying doses of SKF-38393 on $\mathrm{D}_{1}$-dopamine receptor priming. All rats received multiple i.p. doses of SKF-38393 at 4 day intervals. Data for the $3 \mathrm{mg} / \mathrm{kg}$ naive group was obtained after the first $3 \mathrm{mg} / \mathrm{kg}$ dose of SKF-38393. The $1.5 \mathrm{mg} / \mathrm{kg}$ group received six $1.5 \mathrm{mg} /$ $\mathrm{kg}$ doses, the $3.0 \mathrm{mg} / \mathrm{kg}$ group received three $3 \mathrm{mg} / \mathrm{kg}$ doses and the $9 \mathrm{mg} / \mathrm{kg}$ group received one $9 \mathrm{mg} / \mathrm{kg}$ dose of SKF-38393. The responses shown under 'after $9 \mathrm{mg} / \mathrm{kg}$ ' is the response to an additional $3 \mathrm{mg} / \mathrm{kg}$ dose after an accumulated $9 \mathrm{mg} / \mathrm{kg}$ of SKF-38393 had been administered to all groups. Asymptote represents the activity scores from the 3rd additional 3 $\mathrm{mg} / \mathrm{kg}$ dose after the rats had previously received the cumulative dose of $9 \mathrm{mg} / \mathrm{kg}$. Table I can be consulted in order to see the response to intervening treatments with SKF-38393 (i.e. dose 7 for the $1.5 \mathrm{mg} / \mathrm{kg}$ group and doses 4 and 2 for the 3 and $9 \mathrm{mg} / \mathrm{kg}$ groups, respectively). * $P$ $<0.05$ when compared to the $3 \mathrm{mg} / \mathrm{kg}$ naive group. 


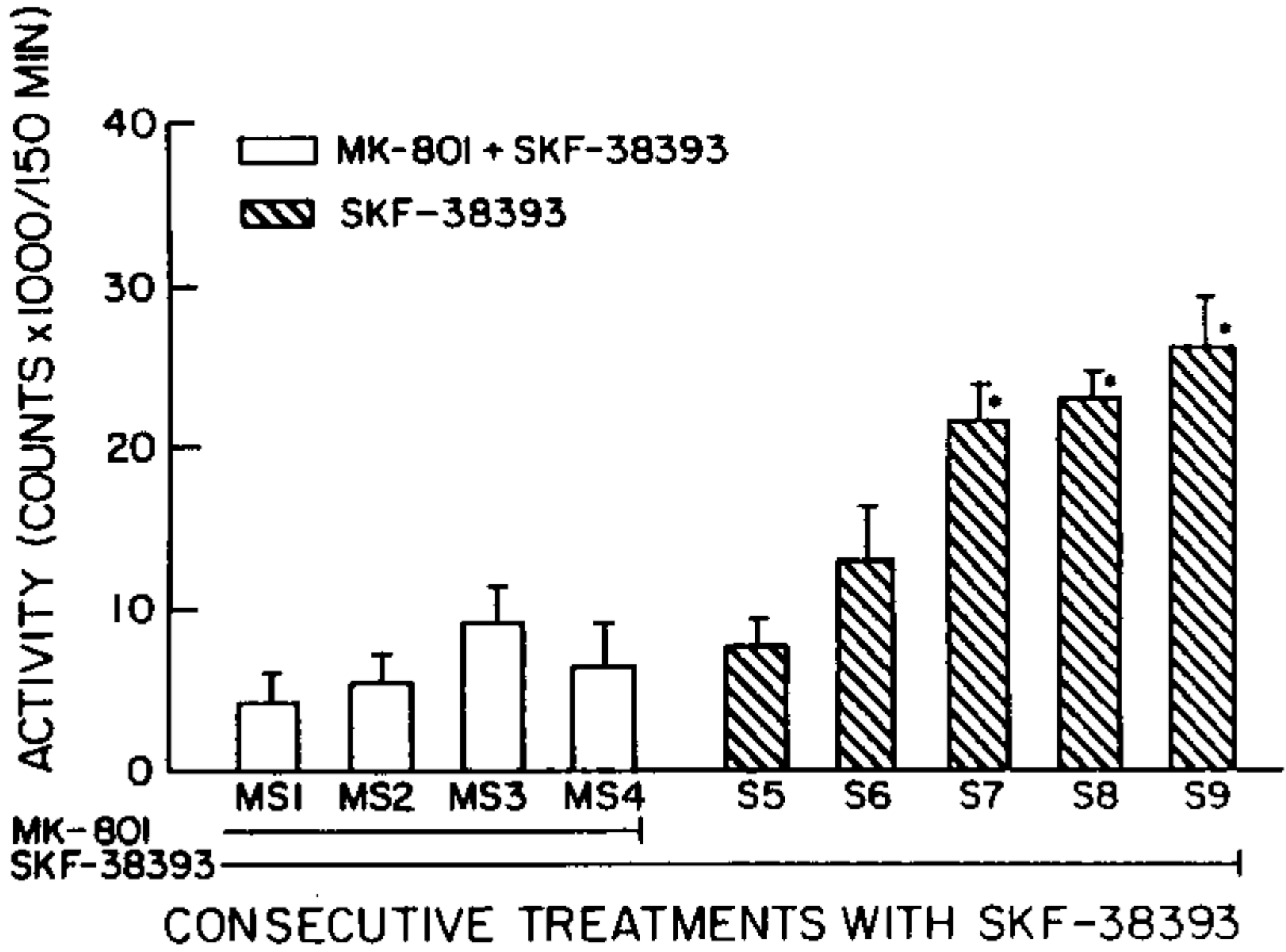

Fig. 3.

Priming of $\mathrm{D}_{1}$-dopamine receptor responses during and after $0.3 \mathrm{mg} / \mathrm{kg} \mathrm{MK}-801$ treatment. The lines below the illustration indicate the course of the drug treatments. Neonatal 6-OHDAlesioned rats received MK-801 (0.3 mg/kg) $30 \mathrm{~min}$ prior to the injection of SKF-38393 (3 mg/ $\mathrm{kg}$ ) for four treatments (MS1 to MS4). Beginning one week after the last treatment combination, the rats received 5 treatments (S5 to S9) of SKF-38393 (3 mg/kg) in the absence of MK-801. The response to the seventh dose of SKF-38393 for the $0.1 \mathrm{mg} / \mathrm{kg}$ MK-801 pretreatment groups (S-7; see Fig. 4) was 17,379 $\pm 3,732$ activity counts $/ 150 \mathrm{~min} \pm$ S.E.M. $(n=4)$. The response for the seventh dose of SKF-38393 for the $1.0 \mathrm{mg} / \mathrm{kg}$ MK-801 treatment groups was $24,514 \pm 4,935$ activity counts $/ 150 \mathrm{~min} \pm$ S.E.M. These values are significantly greater $(P<0.01)$ than the response for the fifth dose of SKF-38393 (see 4B) indicating that priming occurred in these animals. $* P<0.05$ compared to S5 SKF-38393 treatment. 

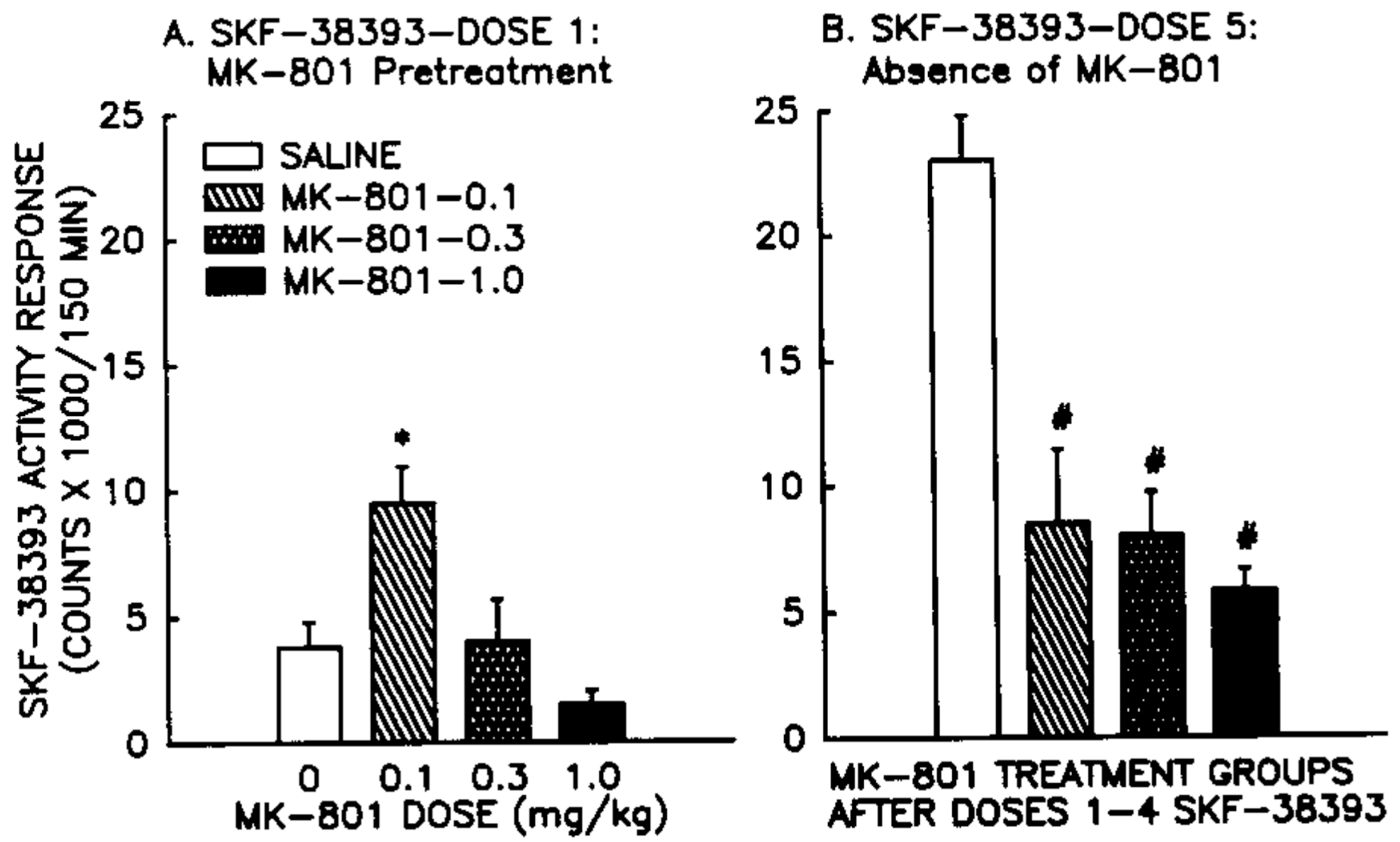

Fig. 4.

Effect of varying doses of MK-801 on priming of SKF-38393-induced activity in neonatal 6OHDA-lesioned rats. (A) illustrates the response to the first dose of SKF-38393 (3 mg/kg) in the absence and presence of MK-801 pretreatment. (B) illustrates the response to the fifth dose of SKF-38393 in the groups in (A) given doses 1-4 of SKF-38393 in the presence of MK-801. The groups in (B) received only SKF-38393 (3 mg/kg). Responses for the first 4 doses of SKF-38393 and subsequent doses of SKF-38393 (i.e., in absence of MK-801) for the $0.3 \mathrm{mg} /$ $\mathrm{kg} \mathrm{MK}-801$ group are presented in Fig. 3. Data indicating that priming of $\mathrm{D}_{1}$-dopamine receptor responses occurred when SKF-38393 was administered alone following 0.1 and $0.3 \mathrm{mg} / \mathrm{kg}$ MK-801/SKF-38393 treatment are presented in Fig. 3 legend. $(0 \mathrm{mg} / \mathrm{kg})$ is a saline-treated group. $* P<0.05$ when compared to $0 \mathrm{mg} / \mathrm{kg}$ group. $* P<0.01$ when compared to $0 \mathrm{mg} / \mathrm{kg}$ group. 


\section{TABLE I}

Activity counts following repeated administration of SKF-38393 to neonatal 6-OHDA-lesioned rats ${ }^{a}$ Counts are per $150 \mathrm{~min}, \pm$ S.E.M.

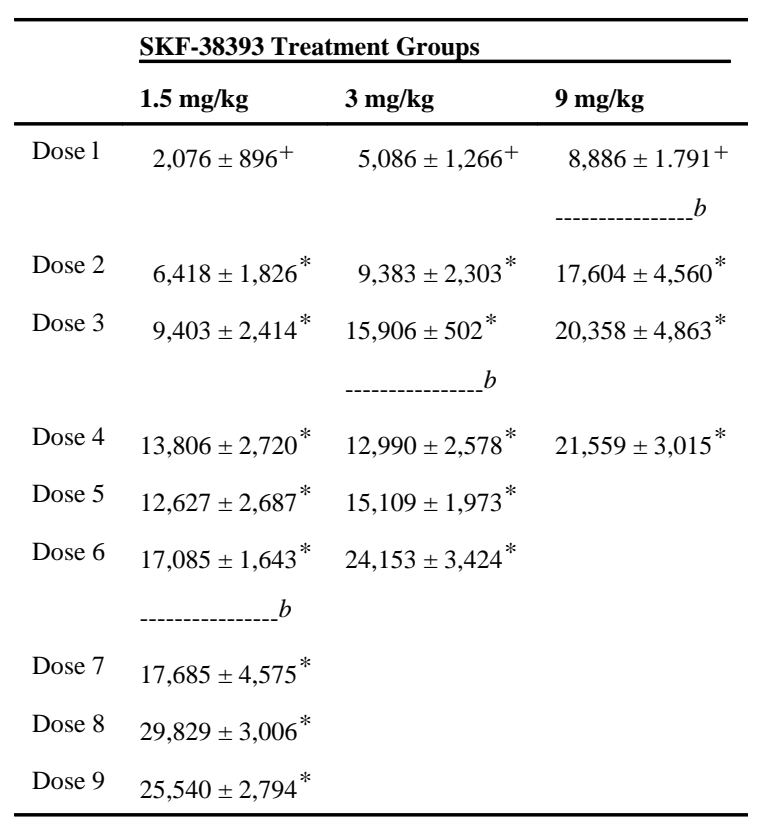

${ }^{a}$ Rats in which dopaminergic neurons had been preferentially reduced were habituated to the activity recording chambers for 50 min immediately before each test session. Various doses of SKF-38393 were then administered i.p. and the rats were returned to the activity recording cages for a 150 min recording session. The 1.5 and $3.0 \mathrm{mg} / \mathrm{kg}$ treatment groups were tested repeatedly with the same dose of SKF-38393 at 4 day intervals until a total of $9 \mathrm{mg} / \mathrm{kg}$ had been given. The $9 \mathrm{mg} / \mathrm{kg}$ treatment group received a single $9 \mathrm{mg} / \mathrm{kg}$ dose. At the dashed line (see ${ }^{b}$ ), a total accumulated dose of $9 \mathrm{mg} / \mathrm{kg}$ had been given for each group. Rats now received an additional 3 doses of $3 \mathrm{mg} / \mathrm{kg}$ of SKF-38393 at 4 day intervals to assess the degree of priming of the $\mathrm{D}_{1}$-dopamine receptor response.

${ }^{b}$ Challenge doses of SKF-38393 (3 mg/kg) were given after a cumulative dose of $9 \mathrm{mg} / \mathrm{kg}$ over the previous sessions had been administered (see ${ }^{a}$ ). The dashed line within each column indicates this treatment change.

${ }^{+}$Activity counts for first dose on day 1 are different from counts obtained in each other treatment group (doses); $P<0.05$.

${ }^{*} P<0.05$ when compared with day 1 of that group. 


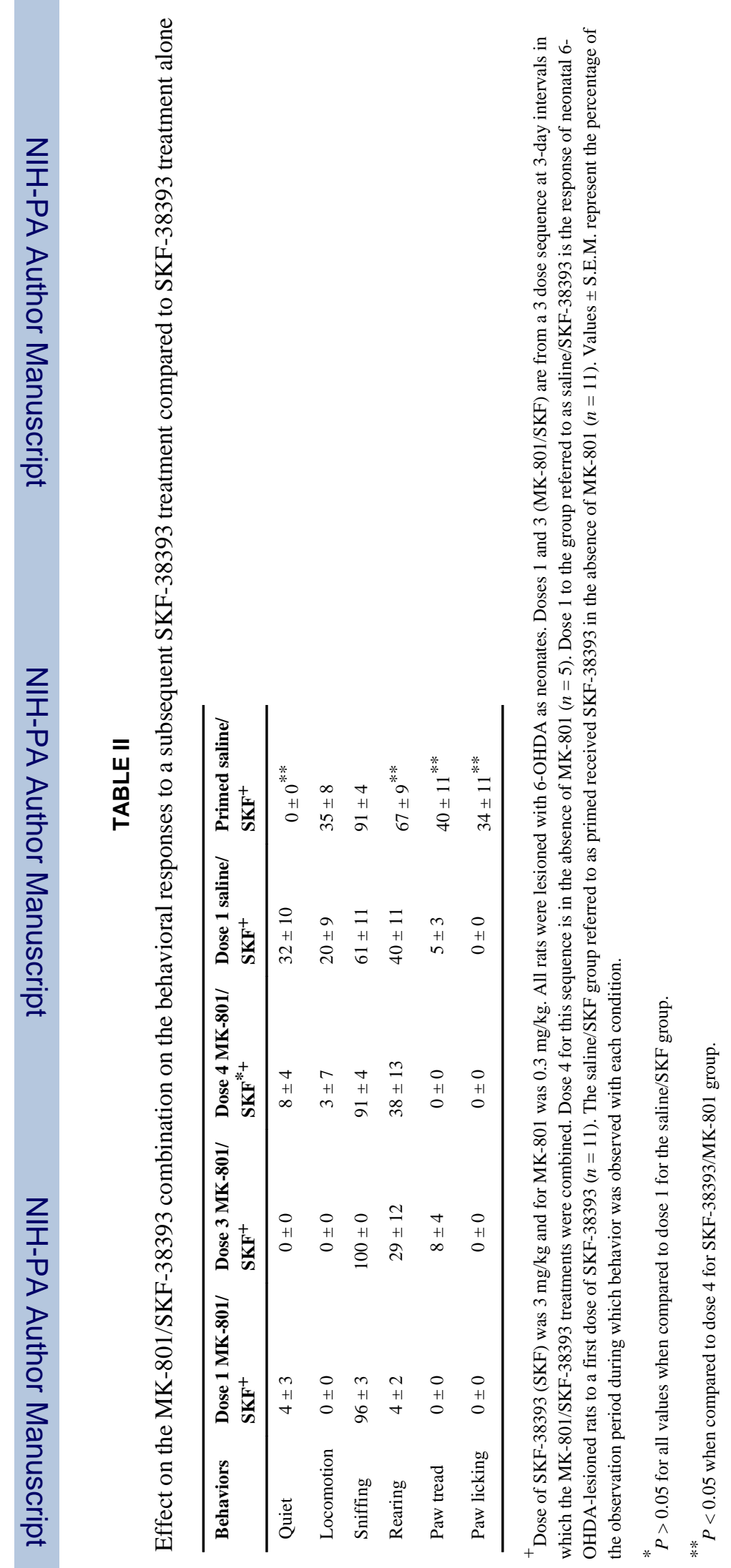

Brain Res. Author manuscript; available in PMC 2010 July 13. 


\section{TABLE III}

Effect increasing doses of MK-801 on the activity response to SKF-38393 in neonatally lesioned rats demonstrating maximal behavioral supersensitivity

\begin{tabular}{llll}
\hline Pretreatment $^{\boldsymbol{a}}$ & $\begin{array}{l}\text { MK-801 } \\
\text { dose } \\
\text { (mg/kg) }\end{array}$ & $\begin{array}{l}\text { Activity response } \boldsymbol{b} \\
\text { (mean } \pm \text { S.E.M.) }\end{array}$ & $\mathbf{n}$ \\
\hline Saline + SKF & - & $24,276 \pm 2,202$ & 5 \\
Saline + quinpirole & - & $17,728 \pm 2,767$ & 4 \\
MK-801 + SKF & 0.1 & $24,314 \pm 5,782$ & 5 \\
& 0.3 & $8,593 \pm 4,115^{*}$ & 4 \\
MK-801 + quinpirole & 0.3 & $2,751 \pm 794^{*}$ & 4 \\
\hline
\end{tabular}

${ }^{a}$ Rats received SKF-38393 (3 mg/kg) or quinpirole $(0.3 \mathrm{mg} / \mathrm{kg})$. Animals were treated previously with SKF-38393 for at least 5 times and were found to be supersensitive to this dose of $\mathrm{D}_{1}$-dopamine agonist. The effect of MK-801 on the quinpirole response was tested in neonatal 6-OHDA-lesioned rats found supersensitive to this $\mathrm{D}_{2}$-dopamine agonist. All rats were treated neonatally to reduce both norepinephrine and dopamine in brain (see Methods).

${ }^{b}$ Activity response is the mean \pm S.E.M. of accumulated counts for the 150 min recording period.

$\stackrel{*}{P}<0.05$ when compared to saline. 